\title{
Kajian Infrastruktur TI Menurut Standar COBIT 5: Studi Kasus Sekolah NanYang Zhi Hui Medan
}

\author{
*Hita ${ }^{1}$, Robin ${ }^{2}$
}

Address: STMIK Mikroskil, Sistem Informasi, Medan, Indonesia ${ }^{1}$, STMIK Mikroskil, Manajemen Informatika, Medan, Indonesia ${ }^{2}$

Email: hita_tan@yahoo.com ${ }^{1}$, robin80wong@yahoo.com²

\begin{abstract}
Abstrak
Saat ini sudah banyak lembaga pendidikan yang memanfatkan teknologi sistem informasi dalam aktivitas akademisnya, baik sekolah-sekolah maupun perguruan tinggi. Pemanfaatan teknologi ini ditujukan untuk menunjang proses pendidikan dan meningkatkan efisiensi dan produktivitas kinerja pendidikan di lembaga pendidikan. Dengan adanya teknologi tersebut, maka perlu diadakannya pengauditan untuk mengetahui tingkat kematangan tata kelola teknologi di lembaga pendidikan tersebut dengan menggunakan tools yang sudah terstandarisasi. Melalui penilaian tersebut sangat diharapkan dapat membawa lembaga pendidikan ke arah pengelolaan yang lebih baik di masa yang akan datang. Metoda Analisis yang digunakan adalah Kerangka kerja COBIT 5. Metode ini digunakan sebagai acuan dalam melakukan evaluasi tata kelola teknologi informasi dan untuk mengukur capability level pada Sekolah Nanyang Zhi Hui Medan. Dari data hasil penilaian capability level masingmasing proses, dilakukan perhitungan untuk mengetahui besarnya rata-rata capability level yang telah dicapai oleh Sekolah Nanyang Zhi Hui Medan. Dari hasil perhitungan, disimpulkan bahwa capability level pada Sekolah Nanyang Zhi Hui saat ini berada di level 2. Dengan demikian makan dapat dinilai bahwa pengelolaan IT di Sekolah Nanyang Zhi Hui ini sudah baik.
\end{abstract}

Keywords - information technology, maturity level, educational institutions

\section{Latar Belakang}

Perkembangan dan pemanfaatan Teknologi Informasi dalam kehidupan masyarakat pada saat sekarang ini sudah meningkat sangat pesat. Ada yang memanfaatkannya hanya untuk gaya hidup, dan ada juga yang menganggapnya sebagai perangkat dan sarana yang penting. Yang memanfaatkan teknologi informasi sudah mencakup ke individu masyarakat dan juga organisasi, baik organisasi sektor bisnis maupun sektor publik.

Bagi organisasi / perusahaan, teknologi informasi merupakan bagian yang sangat signifikan untuk mendukung visi dan misi bisnis organisasi, caranya adalah dengan menyediakan suatu wadah informasi dan komunikasi yang cepat, mudah, dan akurat, proses bisnis juga menjadi lebih efektif dan efisien. Teknologi informasi juga dapat digunakan untuk mendukung pengambilan keputusan dalam organisasi dan meningkatkan inovasi organisasi untuk lebih berkembang.

Sebuah tata kelola IT yang baik akan sangat menjaga fungsi IT untuk memberikan peluang strategis bagi bisnis organisasi. Tata kelola atau governance berfungsi untuk memastikan bahwa segala kebutuhan, kondisi, dan pilihan stakeholder dievaluasi agar sesuai dengan tujuan organisasi, menetapkan hal-hal prioritas dalam pengambilan keputusan, dan memonitor kinerja berdasarkan tujuan dan arahan. 
Salah satu praktik tata kelola IT yang dapat dilakukan oleh organisasi adalah dengan melakukan evaluasi teknologi informasi atau system informasi. Evaluasi bertujuan untuk menilai, memonitor, dan memastikan bahwa sistem informasi perusahaan dapat mengelola integritas data dengan baik dan mampu beroperasi secara efektif sesuai dengan tujuan perusahaan dan tujuan IT perusahaan.

Saat ini sudah banyak lembaga pendidikan yang memanfatkan teknologi sistem informasi dalam aktivitas akademisnya, baik sekolah-sekolah maupun perguruan tinggi. Pemanfaatan teknologi ini ditujukan untuk menunjang proses pendidikan dan meningkatkan efisiensi dan produktivitas kinerja pendidikan di lembaga pendidikan.

Sebagai salah satu bidang yang mempersiapkan sumberdaya manusia, dunia pendidikan dituntut untuk mengkonversikan tacit knowledge yang merupakan pengetahuan yang lahir berdasarkan pengalaman asli (learn by experience) dengan memasukkan elemen-elemen iptek modern sehingga menjadi explisit knowledge yang menghasilkan produk-produk baru sesuai dengan state of the art mutakhir dan kompetitif (Zuhal, 2000).

Sekolah Nanyang Zhi Hui Medan adalah salah satu sekolah swasta terkemuka yang memiliki sistem pembelajaran yang sistematis. Sekolah ini juga telah memanfaatkan TI dalam mendukung proses akademik dan pembelajaran, mulai dari setiap kelas sudah dilengkapi dengan media elektonik seperti komputer dan proyektor LCD untuk mendukung metode belajar dan mengajar para guru kepada para murid. Pihak sekolah juga menggunakan teknologi informasi dalam mengelola sumber daya manusia, memproses data-data administrasi dan data keuangan organisasi sekolah, dan juga proses pengelolaan asset sekolah.

COBIT (Control Objectives for Information and related Technology) merupakan sebuah kerangka kerja IT yang diterbitkan oleh ISACA (Information System Audit and Control Association). COBIT dapat membantu organisasi dalam menciptakan nilai IT yang optimal dengan mewujudkan keseimbangan antara manfaat yang diharapkan dan mengoptimalkan tingkat risiko dan penggunaan sumber daya.

Teknologi informasi dapat didefinisikan sebagai perpaduan antara teknologi komputer dan telekomunikasi dengan teknologi lainnya seperti perangkat keras, perangkat lunak, database, teknologi jaringan, dan peralatan telekomunikasi lainnya (Maharsi 2000). Selanjutnya, teknologi informasi dipakai dalam sistem informasi organisasi untuk menyediakan informasi bagi para pemakai dalam rangka pengambilan keputusan.

\section{Metode}

\subsection{Metode Analisis}

Metoda Analisis yang digunakan dalam laporan ini adalah Kerangka kerja COBIT 5. Metode ini digunakan sebagai acuan dalam melakukan evaluasi tata kelola teknologi informasi dan untuk mengukur capability level pada Sekolah Nanyang Zhi Hui Medan.

\subsection{Kerangka Pikir}

Kerangka berpikir yang digunakan dalam penelitian ini adalah seperti digambarkan pada gambar 1:

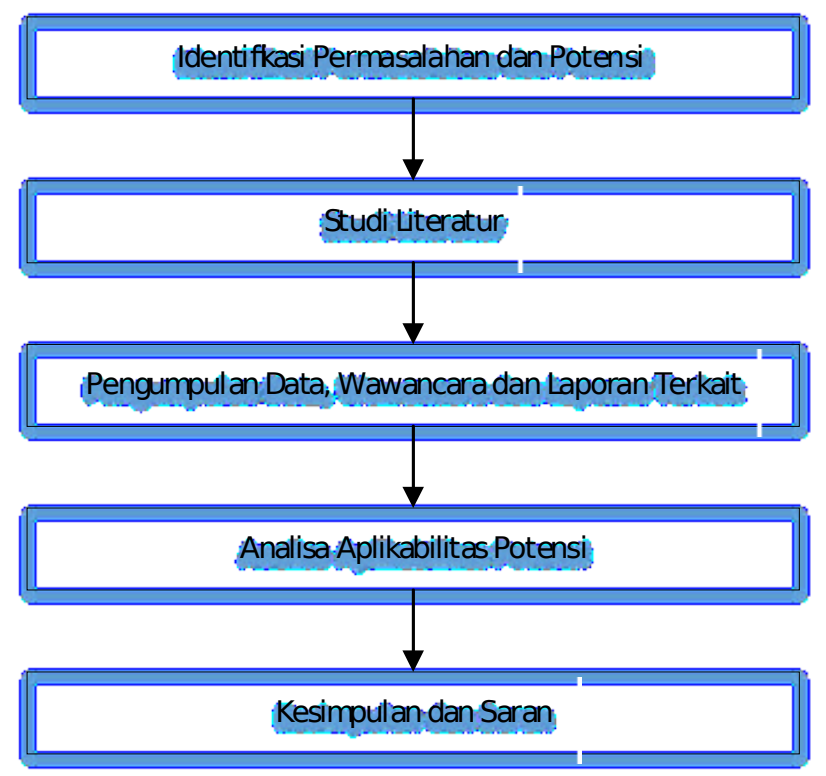

Gambar 1. Kerangka Pikir 


\subsubsection{Identifikasi Permasalahan dan Potensi}

Identifikasi Permasalahan dan Potensi, melakukan kajian terhadap permasalahan dan menganalisa potensi yang dapat diperoleh dengan mempelajari gambaran umum perusahaan, menentukan ruang lingkup evaluasi dengan berdiskusi bersama tim IT dari Sekolah Nanyang Zhi Hui berdasarkan standard COBIT, kemudian membuat rencana evaluasi setelah mengetahui kepastian ruang lingkup, yaitu dengan membuat rancangan perkiraan pekerjaan harian, dan memastikan evaluasi bisa diselesaikan dengan tepat waktu.

\subsubsection{Studi literatur}

Studi literatur, mencari literatur yang bersumber dari jurnal, buku, hasil penelitian sebelumnya dan media informasi lainnya yang sesuai dengan masalah yang terkait penelitian yang akan dilaksanakan untuk menyelesaikan atau menjawab persoalan.

\subsubsection{Pengumpulan Data}

Pengumpulan data, melakukan wawancara, observasi, dan mempelajari dokumendokumen perusahaan seperti SOP, kebijakankebijakan, dan hasil-hasil audit sebelumnya. Hal ini dilakukan sepanjang proses evaluasi dengan meminta data yang dibutuhkan kepada Tim IT. Setelah mendapatkan buktibukti pendukung untuk melakukan penilaian level kapabilitas, semua proses dihitung level kapabilitasnya.

\subsubsection{Kesimpulan dan Saran}

Kesimpulan dan Saran, menganalisa perbedaan level kapabilitas proses Sekolah Nanyang Zhi Hui dengan target yang telah ditentukan. Setelah perbedaan level diketahui, analisa mengenai saran dan rekomendasi yang bisa menaikkan level kapabilitas proses Sekolah Nanyang Zhi Hui sehingga mencapai target bisa dilakukan. Setelah saran dan rekomendasi untuk setiap proses diketahui, hasil laporan akhir tersebut diberikan kepada tim IT.

\section{Hasil}

\subsection{Pemetaan Struktur Organisasi terhadap Proses COBIT}

Dari hasil penjelasan mengenai pemetaan bagian-bagian dari Dari daftar-daftar proses yang akan dievaluasi maka dilakukanlah pemetaan keterlibatan masing-masing bagian dari struktur organisasi terhadap proses COBIT agar mempermudah pengumpulan data-data pada Sekolah Nanyang Zhi Hui Medan dan proses evaluasi yang dilakukan menjadi lebih jelas mengenai data-data yang diperlukan tersebut diambil dari divisi yang bersangkutan.

Struktur organisasi yang terlibat di dalam masing-masing proses COBIT, berikut ini adalah tabel rangkuman pemetaannya:

Tabel 1. Pemetaan Proses COBIT terhadap struktur organisasi

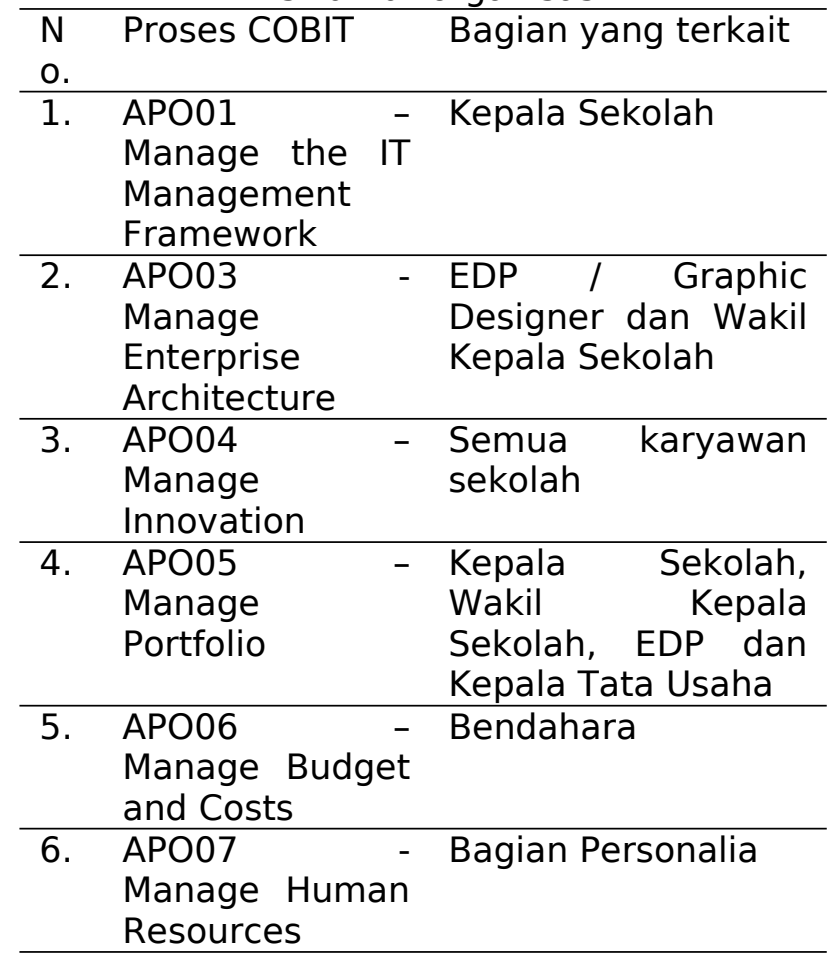

\subsection{Analisis Kebutuhan Dokumen untuk Pelaksanaan Evaluasi}

Dalam mencapai level kapabilitas 1, aktivitas yang harus dilakukan adalah melakukan pengecekan terhadap proses-proses COBIT apakah telah dilakukan atau belum dilakukan pada Sekolah Nanyang Zhi Hui Medan. 6 
proses yang dianalisis dan dinilai pada Sekolah Nanyang Zhi Hui Medan adalah:

\section{APO01 - Manage the IT Management Framework}

Adalah proses menjaga tata kelola IT perusahaan, mekanisme dan otoritas dalam mengelola informasi dan penggunaan IT dalam perusahaan agar sejalan dengan kebijakan dan prosedur yang berlaku. Daftar sub-proses yang diambil dokumennya sebagai bukti bahwa proses ini telah mencapai level kapabilitas 1 adalah:

1. APO01.01 - Define the Organisational Structure.

2. APO01.02 - Establish Roles and Responsibilities.

3. APO01.03 - Maintain the Enablers of The Management System.

4. APO01.04 - Communicate Management Objectives and Direction.

5. APO01.05 - Optimisation the Placement of the IT Function.

6. APO01.06 - Define Information(data) and System Ownership.

7. APO01.07 - Manage Continual Improvement of Processes.

8. APO01.08 - Ensure Compliance with Policies and Procedures.

\section{APO03-Manage Architecture}

Enterprise

Adalah proses membuat kerangka kerja umum yang mencakup proses bisnis, informasi, data aplikasi, dan arsitektur teknologi untuk mewujudkan strategi perusahaan dan strategi IT. Daftar sub-proses yang diambil dokumennya sebagai bukti bahwa proses ini telah mencapai level kapabilitas 1 adalah:

1. AP003.01 - Develop the enterprise architechture vision

2. APO03.02 - Define reference architechture 3. APO03.03 - Select opportunities and solutions

4. APO03.04 - Define architechture implementation

5. APO03.05 - Provide enterprise architechture services

\section{APO04 - Manage Innovation}

Adalah proses menyadari dan menganalisis tren IT dengan tujuan untuk dapat mengidentifikasi kesempatan dalam berinovasi, dan membuat perencanaan untuk mendapatkan keuntungan dari inovasi tersebut. Daftar sub-proses yang diambil dokumennya sebagai bukti bahwa proses ini telah mencapai level kapabilitas 1 adalah:

1. APO04.01 Create an environment conducive to innovation.

2. APO04.02 Maintain and understanding of the enterprise environment.

3. APO04.03 Monitor and scan the technology environment.

4. APO04.04 Assess the potential of emerging technologies and innovation ideas.

5. APO04.05 Recommend appropriate further initiatives.

6. APO04.06 Monitor the implementation and use of innovation.

\section{APO05 - Manage Portfolio}

Adalah proses menjalankan strategi jangka panjang yang sejalan dengan EA dan berfokus dalam memikirkan kebutuhan sumber daya dan pendanaannya. Proses yang dilakukan termasuk mengevaluasi dan mengatur prioritas, memantau perkembangan, dan mengajukan perubahan bila dibutuhkan. Daftar sub-proses yang diambil dokumennya sebagai bukti bahwa proses ini telah mencapai level kapabilitas 1 adalah:

1. APO05.01 - Establish Target Investment Mix.

2. APO05.02 - Determine The Availability and Sources of Funds.

3. APO05.03 - Evaluate and Select Programmes to Fund.

4. APO05.04 - Monitor, Optimise and Report on Investment Portfolio Investment.

5. APO05.05 - Maintain Portfolios.

6. APO05.06 - Manage Benefits Achievement.

\section{APO06 - Manage Budget and Costs}

Adalah proses mengelola aktivitas keuangan terkait dengan IT, termasuk anggaran, manajemen biaya dan manfaat, dan penggunaan praktik-praktik formal, adil dan wajar dalam pengelolaan biaya. Daftar subproses yang diambil dokumennya sebagai bukti bahwa proses ini telah mencapai level kapabilitas 1 adalah:

1. APO06.01 - Manage finance and accounting.

2. APO06.02 - Prioritise resource allocations.

3. APO06.03 - Create and maintain budgets.

4. APO06.04 - Model and allocate costs.

5. APO06.05 - Manage costs.

\section{APO07 - Manage Human Resources}


Adalah proses menyediakan pendekatan terstruktur untuk mendapatkan struktur, penempatan, hak, dan kemampuan yang optimal dari sumber daya manusia. Termasuk di dalamnya mengkomunikasikan peran dan tanggung jawab, rencana perkembangan karir, dan ekspektasi performa kerja. Daftar sub-proses yang diambil dokumennya sebagai bukti bahwa proses ini telah mencapai level kapabilitas 1 adalah:

1. APO07.01 - Maintain adequate and appropriate staffing.

2. APO07.02 - Identify key IT personnel.

3. APO07.03 - Maintain the skills and competencies of personnel.

4. AP007.04 - Evaluate employee job performance.

5. APO07.05 - Plan and track the usage of IT and business human resources.

6. AP007.06 - Manage contract staff.

Untuk penilaian level kapabilitas 2 sampai dengan level 5, dokumen-dokumen yang dibutuhkan untuk penilaian dan sekaligus berperan sebagai bukti pengelolaan proses yang dilaksanakan tersebut adalah:

1. Dokumentasi proses: Nama proses, pemilik proses, ruang lingkup proses, peranan proses, peta proses, diagram RACl, matriks control internal, dan prosedur proses.

2. Rencana proses: Tujuan performa proses, pengurusan sumber daya proses, komunikasi proses, infrastruktur proses, lingkungan kerja, kebutuhan kemampuan dan pengalaman, dan kebutuhan pelatihan.

3. Rencana kualitas: Pernyataan kebijakan kualitas dan tujuan, isi hasil kerja, kriteria kualitas hasil kerja sebagai dasar review dan persetujuan, dokumentasi hasil kerja, dan pengendalian perubahan hasil kerja.

4. Catatan kualitas: Catatan review hasil kerja terhadap ketentuan dan tindakan yang diambil.

5. Kebijakan dan standar: Tujuan dan tanggung jawab proses, batas performa minimum proses, pemetaan proses standar, termasuk urutan yang diharapkan dan interaksi antar proses, prosedur yang terstandarisasi, peran dan kompetensi yang dibutuhkan untuk melakukan proses, infrastruktur dan lingkungan kerja untuk melakukan proses, ketentuan pelaporan dan pemantauan termasuk audit.

6. Rencana peningkatan proses: Tujuan peningkatan proses, analisis terhadap best practice, kesempatan pengembangan teknologi, tindakan peningkatan, rencana implementasi peningkatan, dan pendekatan kualitas proyek.

7. Rencana pengukuran proses: Tujuan pengukuran, indicator pengukuran yang disarankan, prosedur pengumpulan data, dan prosedur analisis.

8. Rencana pengendalian proses: Teknik pengendalian, pendekatan pengukuran, dan batasan performa normal.

9. Catatan performa proses: Catatan review terhadap ketentuan dan tindakan yang diambil.

Perincian dari dokumen yang dibutuhkan untuk penilaian masing-masing level adalah sebagai berikut:

1. Level 2: 1, 2, 3, dan 4.

2. Level 3: 1, 2, 4, 5, dan 9.

3. Level 4: 1, 6, 7, 8, dan 9.

4. Level 5: 9.

\subsection{Hasil Perhitungan Capability Level}

Capability level yang telah dicapai oleh Sekolah Nanyang Zhi Hui Medan berdasarkan hasil perhitungan 6 proses COBIT yang dievaluasi adalah semuanya mencapai level 2. Penulis membuat target capability level untuk semua prosses yang dievaluasi pada Sekolah Nana Yang Zhi Hui adalah mencapai level 3.

Tabel 2 Daftar Capability Level untuk semua proses COBIT

\begin{tabular}{llccc}
\hline No & \multicolumn{1}{c}{ Nama Proses } & $\begin{array}{r}\text { Target } \\
\text { Level }\end{array}$ & $\begin{array}{c}\text { Level } \\
\text { Saat } \\
\text { Ini }\end{array}$ & Gap \\
\hline $\mathbf{1}$ & $\begin{array}{l}\text { APO01 - Manage the } \\
\text { Management }\end{array}$ & 3 & 2 & $\mathbf{1}$ \\
$\mathbf{2}$ & APO03-Manage & 3 & 2 & $\mathbf{1}$ \\
$\mathbf{3}$ & APO04 - Manage & 3 & 2 & $\mathbf{1}$ \\
$\mathbf{4}$ & APO05 - Manage & 3 & 2 & $\mathbf{1}$ \\
$\mathbf{5}$ & APO06 - Manage & 3 & 2 & $\mathbf{1}$ \\
$\mathbf{6}$ & APO07 - Manage & 3 & 2 & $\mathbf{1}$ \\
\hline
\end{tabular}

Berdasarkan data hasil penilaian capability level masing-masing proses, maka dilakukanlah perhitungan untuk mengetahui besarnya rata-rata capability level yang telah dicapai oleh Sekolah Nanyang Zhi Hui Medan. Perhitungan dilakukan dengan rumus ratarata sebagai berikut:

Perhitungan Capability Level 
Capability Level $=(0 * \mathrm{y} 0)+(1 * \mathrm{y} 1)+\ldots+$ (5*y5)

\section{Z}

Keterangan:

yn $(\mathrm{y} 0 \ldots \mathrm{y} 5)=$ jumlah proses yang berada dilevel $n$

$\mathrm{z}=$ jumlah proses yang dievaluasi

Berdasarkan data pencapaian level masingmasing proses, maka perhitungan rata-rata capability level adalah sebagai berikut:

Capability Level $=(0 * 0)+(1 * 0)+(2 * 6)+(3 * 0)$

$$
+(4 * 0)+(5 * 0)
$$

Capability Level $=2$

6

Dari hasil perhitungan, maka dapat disimpulkan bahwa capability level pada Sekolah Nanyang Zhi Hui saat ini berada di level 2 dan memiliki gap sebesar 1 untuk mencapai level 3,00 yang menjadi target capability level penulis.

Di dalam COBIT tidak diidentifikasi prosesproses apa saja yang harus menjadi prioritas suatu perusahaan, karena prioritas prose situ tergantung kepada kebutuhan daripada perusahaan itu sendiri berdasarkan kegiatan operasional suatu perusahaan. Terdapat dua alternatif pilihan yang dapat dilakukan oleh sekolah Nanyang Zhi Hui, yaitu:

1. Quick Win \& alternatif pilihan ini dilakukan jika prioritas kebutuhan sekolah adalah pencapaian rating.

Dalam upaya mencapai target capability level, disarankan sekolah membuat SOP demi tercapainya persyaratan level 3 untuk 6 proses-proses tersebut:

a. APOO1 -- Manage the Management Framework for IT

b. APO03 -- Manage Enterprise Architecture

c. APO04 - Manage Innovation

d. APO05 - Manage Portfolio

e. APO06 - Manage Budget and Costs

f. APO07 - Manage Human Resources

2. Apabila kebutuhan sekolah adalah merapikan keseluruhan tata kelola IT, maka prioritas dapat dipilih sesuai goals yang ada di sekolah dan dimulai dari proses yang memiliki dampak besar bagi sekolah.

Sekolah sebaiknya memperbaiki tata kelola IT dimulai dengan melengkapi semua output yang belum dicapai pada level 1 , selanjutnya perusahaan dapat berfokus pada prosesproses yang berada di level 2 saat ini dan melakukan perbaikan untuk mencapai level 3, kemudian diikuti dengan peningkatan proses yang saat ini telah mencapai level 3 agar dapat memperoleh level selanjutnya.

\section{Kesimpulan}

Berdasarkan evaluasi penilaian yang sudah dilakukan di Sekolah Nanyang Zhi Hui maka penulis mengambil beberapa kesimpulan berikut ini :

1. Dengan menggunakan capability level pada framework COBIT didapatlah capability level di Sekolah Nanyang Zhi Hui adalah berada pada level 2 (managed process), dengan nilai 2. Semua proses berada pada level 2. Dengan demikian makan dapat dinilai bahwa pengelolaan IT di Sekolah Nanyang Zhi Hui ini sudah baik.

2. Dari perhitungan capability level didapat nilai 2, sedangkan target yang ditentukan penulis adalah 3 . Dengan demikian terdapat perbedaan sebesar 1 . Untuk memperbaiki perbedaan nilai itu, diharapkan ke depannya sekolah akan memnyusun dan menetapkan pedoman berupa SOP yang sesuai dan berdasarkan panduan dari COBIT 5 untuk semua proses.

\section{References}

[1] Fitrianah , D \& Sucahyo, Y. G. Audit Sistem Informasi / Teknologi dengan Kerangka Kerja COBIT untuk Evaluasi Manajemen Teknologi Informasi di Universitas $\mathrm{XYZ}$, Jurnal Sistem Informasi MTI-UI, Volume 4, Nomor 1, ISBN 14128896.

[2] Hall, J.A. (2007). Audit Teknologi Informasi dan Assurance. (edisi-2), Dewi Fitriasari(ed.), \& Deny Arnos Kwary(ed.). Jakarta: Penerbit Salemba Empat.

[3] IT Governance Institute (2007b), “IT Governance Implemetation Guide", IT Governance Institute.

[4] IT Governance Institute, 2000. Management Guidelines, Third Edition, USA.

[5] IT Governance Institute, 2005. Cobit 4.0, Illionis, USA.

[6] ISACA. (2012). COBIT 5 A Business Framework for the Governance and Management of Enterprise IT. USA: ISACA. 
[7] ISACA. (2012). COBIT 5 Enabling Processes. USA: ISACA.

[8] ISACA. (2012). COBIT 5 Implementation. USA: ISACA.

[9] ISACA. (2011). COBIT Process Assessment Model (PAM) Using COBIT 4.1. USA: ISACA.

[10] ISACA. (2011). COBIT Self-Assessment Guide: Using COBIT 4.1. USA: ISACA.

[11] ISACA (2011). 3. COBIT 5-Selfassessment Templates. USA : ISACA.

[12] ISACA. (2011). ISACA issues COBIT process assessment model. Technology \& Business Journal, , 325.

[13] ISACA (1022) COBIT ${ }^{\circledR} \quad 5:$ The Framework Exposure Draft :USA, ISACA.

[14] ISACA (2013). COBIT Self-Assessment Guide: Using COBIT 5. USA: ISACA.

[15] Muhammad Aditya (2012). Panduan Evaluasi Kematangan Proses TIK Universitas Negeri Semarang Berbasis Kerangka Kerja COBIT : UNNES.

[16] Setiawan, Alexander. Evaluasi Penerapan Teknologi Informasi di Perguruan Tinggi Swasta Yogyakarta dengan Menggunakan COBIT Framework. Tesis Tidak Terpublikasi. Yogyakarta: Universitas Gadjah Mada. 2008.

[17] Saptadi, N. Tri. Evaluasi Implementasi Teknologi Informasi Pada Rumah Sakit Bethesda Yogyakarta Menggunakan Cobit Framework dan Expert Choice. Tesis Tidak Terpublikasi. Yogyakarta: Universitas Gadjah Mada. 2007.
[18] Williams, B.K., \& Sawyer, S.C. (2007). Using Information Technology : Pengenalan Praktis Dunia Komputer dan Komunikasi. (edisi-7). Yogyakarta : ANDI.

Hita Lahir di Medan, 11 Februari 1982. Pendidikan Strata 1 (S1) Program Studi Sistem Informasi di STMIK Mikroskil dan Strata 2 (S2) Magister Teknik Informatikadi Universitas Bina Nusantara. Hita adalah seorang dosen dan peneliti di STMIK Mikroskil pada bidang teknologi infrastruktur bisnis

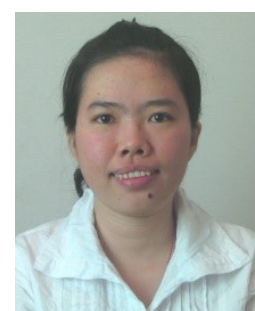

Robin Lahir di Medan, 16

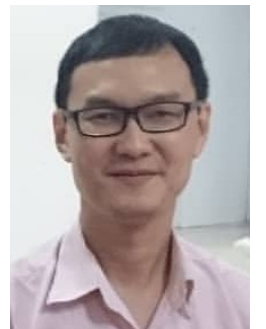
Oktober 1980. Pendidikan Strata 1 (S1) Program Studi Teknik Informatika di STMIK Mikroskil dan Strata 2 (S2) Magister Teknik Informatikadi Universitas Bina Nusantara. Bidang keahlian dan penelitiannya hingga saat ini adalah bahasa pemrograman assembly, pengolahan citra, game engine technology dan visi computer. 